\title{
EDUCATION FOR LUPUS PATIENTS: GETTING THROUGH THE COVID- 19 PANDEMIC
}

Juliana Lacerda de Oliveira Campos ${ }^{1}$, Henrique Trindade Dutra ${ }^{1}$, Agatha Oluwakemi da Silva Soyombo ${ }^{1}$, Giovanna Braghini Pardini ${ }^{1}$, Mariana Caetano Chaves $^{1}$, Patricia Oliveira Lamas ${ }^{1}$, Caio Carvalhais Chaves ${ }^{1}$, Guilherme Costa Ferreira ${ }^{1}$, Luiza Silame Corte ${ }^{1}$, Nathan Shuenck Silva de Oliveira ${ }^{1}$, Gilberto Carvalho Boaventura ${ }^{1}$, Debora Cerqueira Calderaro ${ }^{1}$, Fabiana de Miranda Moura ${ }^{1}$, Rosa Weiss Telles ${ }^{1}$, Cristina Costa Duarte Lanna ${ }^{1, *}$

1.Universidade Federal de Minas Gerais, Belo Horizonte (MG), Brazil.

*Corresponding author: durtelanna@gmail.com

\section{BACKGROUND}

Since March 2020, the novel coronavirus disease (COVID-19) pandemic forced the adoption of restrictive measures to protect susceptible people and interrupt the transmission route. Considering social networks as a powerful source of information and that lupus patients have higher risk of infections, we present two projects of health education for lupus patients to provide useful information about the COVID-19 pandemic.

\section{MATERIALS AND METHODS}

For the last 8 years rheumatology professors and students of medical school have been working on a Health Education Program for lupus patients and their families to provide reliable information about systemic lupus, some comorbidities and general health, using lay language and illustrations. Since March 2020, we included information about COVID-19. In the Waiting Room Project (created on February 2012) printed leaflets are provided to patients at the rheumatology unit as they wait for their appointment. During the COVID-19 pandemic these leaflets were published on social media and on the university website. In the Social Media and Health Education Project (created on July 2018) contents are posted on Facebook page and Instagram profile as "posts", "IGTV" and "stories".

\section{RESULTS}

In 2020, 46 posts were shared until September 14th. Twenty-six concerning COVID-19, 6 in the "Health Tips" section, 10 in the "Learning More" section, one about "World Lupus Day" and 3 "IGTV" videos. Also, 45 "stories" were produced, 16 about COVID-19. The Instagram page achieved 950 followers and reached about 505 people weekly. $89 \%$ were women, aged between 25 and 44 years (64\%), mainly living in Brazil (97\%). Considering the Instagram metrics, there were 1883 interactions with the posts in the feed, with an average reach for each publication of 365 accounts. The posts about COVID-19 have the greater reach on the page, with an average of 400 accounts reached per publication and 1284 interactions. There was a $34 \%$ increase in the number of followers in the last quarter. Also, two leaflets about COVID-19 were produced and published on line. The first one contains general guidance, such as prevention, transmission, symptoms, management, and how to access online medical consultation. The second approaches lupus treatment in this pandemic context.

\section{CONCLUSION}

In this scenario of social isolation, the dissemination of accurate COVID-19 information by social media and leaflets improved the understanding of lupus patients about both diseases. Patients actively participated in the projects, sending questions and sharing experiences. Furthermore, the projects provided an opportunity to medical students to interact with patients.

\section{ACKNOWLEDGEMENTS}

The authors thank the team of UFMG School of Medicine Social Communication Advisory. 


\section{REFERENCES}

1. Balatsoukas P, Kennedy CM, Buchan I, Powell J, Ainsworth J. The role of social network technologies in online health promotion: a narrative review of theoretical and empirical factors influencing intervention effectiveness. J Med Internet Res. 2015;17(6):e141. https://doi.org/10.2196/jmir.3662

1. Santarossa S, Woodruff SJ. \#LancerHealth: Using Twitter and Instagram as a tool in a campus wide health promotion initiative. J Public Health Res. 2018;7(1):1166. https://doi.org/10.4081/jphr.2018.1166

1. Jung J-Y, Yoon D, Choi Y, Kim H-A, Suh C-H. Associated clinical factors for serious infections in patients with systemic lupus erythematosus. Sci Rep. 2019;9:9704. https://doi.org/10.1038/s41598-019-46039-5 